PONTIFÍCIA UNIVERSIDADE CATÓLICA do RIO dE JANEIRO

A influência dos Sócios Torcedores no Um estudo no Clube de Regatas do Flamengo

Patrick Levental Wandelli

Trabalho de Conclusão de Curso

Centro de CIÊnCIAS SOCIAIS - CCS

DEPARTAMENTO DE ADMINISTRAÇÃo

Graduação em Administração de Empresas 
Patrick Levental Wandelli

\title{
A influência dos Sócios Torcedores no futebol Um estudo no Clube de Regatas do Flamengo
}

\author{
Trabalho de Conclusão de Curso
}

Trabalho de Conclusão de Curso, apresentado ao programa de graduação em Administração da PUC-Rio como requisito parcial para a obtenção do titulo de graduação em Administração.

Orientador(a) : Marco Aurélio de Sá

Rio de Janeiro

Dezembro de 2016. 
"Supõe-se que todas as alegrias se parecem. Mas a verdade é que a alegria rubro-negra não se parece com nenhuma outra. Não sei se é funda, ou mais dilacerada, ou mais santa. Só sei que é diferente...".

Nelson Rodrigues 


\section{Agradecimentos}

Acredito sinceramente, que a vida é um sopro, e devido a isso deve ser aproveitada sempre em seu ápice durante toda a nossa trajetória. Para isso contamos com pessoas especiais que dão sentido a nossa vida de alguma forma.

Dito isso, acredito piamente que todas elas me ajudaram de alguma maneira neste processo fundamental da minha vida, e este é o espaço ideal em que posso, com meras lembranças, tentar eternizar minha imensa a gratidão a cada um.

Primeiramente, gostaria de agradecer a todo o apoio e base de tudo em minha vida que são meus pais, Carlos e Liliane, pois sem eles, eu não seria nada

Às minhas irmãs Caroline, mais presente, que acompanhou de perto todo esse percurso me dando forças pra continuar e à caçula Raffaela, que mesmo mais ausente, sempre enviou muita positividade nessa caminhada.

Aos meus avós paternos Alcyreno e Ana Maria que protagonizam até hoje grande parte dos melhores momentos de alegria, carrego em meu braço, eternizado, o nome do patriarca da família; a minha vó materna Marsy que é uma grande companheira e amiga durante toda a minha vida e ao meu avô materno Jayme que lá de cima, tenho certeza que está orgulhoso do neto de tantas maneiras diferentes.

A todos os meus tios e "dindos" que graças a Deus são quatro e todos me completam de maneira distinta, são eles: Mauricio, Mauro, André e Carlos Eduardo, grandes amigos acima de tudo na jornada da vida.

À minha namorada Ana Carolina, pelo dom da palavra quase que sempre, me apoiando e dando força para a conclusão de um trabalho tão marcante em minha trajetória e pelo amor que temos um pro outro, claro.

$\mathrm{E}$ é claro a todos os meus grandes amigos de longa e média data que representam o que sou hoje, são eles: Guilherme, Vitinho, Quiroz, Falcão, Igor, Gabriel, Caio Crazy, Leo, Marquinho, Love, Lucas, Rama, Thais, Joca, Theus e Tati. 


\section{Resumo}

Wandelli, Patrick. A influência dos sócios torcedores no futebol e Um estudo no Clube de Regatas do Flamengo. Rio de Janeiro, 2016. 40 p. Trabalho de Conclusão de Curso - Departamento de Administração. Pontifícia Universidade Católica do Rio de Janeiro.

Este trabalho tem o intuito de ajudar a melhor compreender um pouco das praticas no mundo do futebol, em especial à pratica consolidada em todo o mundo que são os programas de sócios torcedores. Com o foco no Clube de Regatas do Flamengo do Rio de Janeiro, o estudo explorará os fatores que fazem com que torcedores comuns, se fidelizem e virem ativos do clube. Será analisado o processo de tomada de decisão e o comportamento do consumidor nesse caso especifico, devido ao pouco sucesso do clube, comparado ao tamanho de sua torcida. Trata-se de uma pesquisa qualitativa do tipo Análise de Discurso.

Palavras- chave

Flamengo, futebol, sócio torcedor, clubes, torcida, pesquisa qualitativa

\section{Abstract}

Wandelli, Patrick. The influence of officials supporters in football e A study at Clube de Regatas do Flamengo. Rio de Janeiro, 2016. 40 p. Trabalho de Conclusão de Curso - Departamento de Administração. Pontifícia Universidade Católica do Rio de Janeiro.

This work is intended to help to better understand some of the practices in the world of football, specially the stablished practice around the world that are the supporters programs ("club members"). With a focus on Clube de Regatas do Flamengo, from Rio de Janeiro, the study will explore the factors that make commom fans loyal and become active members of the club. The decision-making process and consumer behavior in this particular case will be analyzed due to the club's lack of sucess compared to the size of its fans. This is a qualitative research of the Discourse Analysis type

\section{Key-words}

Supporters, fans, football, soccer, flamengo, club members, qualitative research 


\section{Sumário}

1. O tema e o problema de estudo 1

1.1. Introdução ao tema e ao problema do estudo 1

1.2. Objetivo do estudo 3

1.3. Objetivos intermediários do estudo 3

1.4. Delimitação e foco do estudo 4

1.5. Relevância do Estudo 5

2 . Revisão de Literatura 6

2.1. Marketing 6

2.2. Marketing de Serviços 8

2.3. Comportamento do Consumidor 11

2.4. Comportamento do Consumidor Como Fã 12

2.5. Processo de Decisão de Compra 15

$\begin{array}{ll}\text { 2.6. Brand Equity } & 17\end{array}$

2.7. Brand Image $\quad 21$

2.8. Blogs; Revistas; Jornais esportivos e Sites 23

3-Métodos e procedimentos de coleta e de análise de dados 24

3.1- Etapas de coleta de dados 26

3.2- Fontes de informação selecionadas para coleta de dados 26

3.3- Procedimentos e instrumentos de coleta de dados 27

3.4-Formas de tratamento e análise dos dados coletados 27

3.5-Limitações do Estudo 27

4. Apresentação e análise dos resultados 29

4.1. Relatório da pesquisa qualitativa 29

5.Conclusão 35

6. Referências Bibliográficas 36

$\begin{array}{ll}\text { Anexo } 1 & 40\end{array}$ 
Lista de figuras

Figura 1 - As 4 Caracterisiticas dos Serviços 


\section{O tema e o problema de estudo}

Esse capítulo volta-se à apresentação do tema que se pretende desenvolver e do problema de estudo.

Assim, apresenta-se o problema que suscitou a proposta de investigação e respectivos objetivos de pesquisa. Na sequência, são indicadas as suposições e as hipóteses do estudo e se informa a relevância e justificativa do estudo e a delimitação e foco do estudo.

\subsection{Introdução ao tema e ao problema do estudo}

O universo do futebol no Brasil sempre teve grande impacto em todas as esferas da sociedade, de diferentes formas, seja ela, econômica, passional ou profissional.

O futebol move pessoas pelo mundo todo ao decorrer de um ano inteiro, mexendo com a emoção e paixão de bilhões de seres humanos; não por acaso é o esporte mais popular da face da Terra, devido a todas as suas vertentes e características únicas e todas as culturas que mantém laços com tal esporte.

Dentro desse amplo cenário que é o futebol, existem varias práticas tomadas pelos clubes ao redor do mundo, que constituem o faturamento dos clubes anualmente.

Dado esse fato, os clubes basicamente se enriquecem com a venda de jogadores, contratos de televisão, patrocínios diversos, marketing e com sócios torcedores, que nos grandes clubes internacionais como o Real Madrid e Manchester United, por exemplo, constituem suas maiores receitas, advindas, principalmente de seus sócios torcedores do clube, que se tornam os principais ativos do mesmo. (http://blogs.diariodepernambuco.com.br/esportes/2017/01/23/os-20clubes-mais-ricos-do-mundo-com-o-manchester-united-no-topo-apos-12anos/) 
No Brasil, essa prática foi adotada inicialmente pelos clubes do Sul do país, como Grêmio e Internacional de Porto Alegre, e de uns anos para cá, começou a ser difundida em todo país como uma prática sólida e praticamente obrigatória em todos os grandes clubes do país.

Atualmente, podemos observar que os clubes com os maiores índices e faturamento vindo dos sócios torcedores no Brasil, são os clubes de São Paulo, como Palmeiras, São Paulo, Corinthians e os do Sul já ditos anteriormente. (http://historicofutebolmelhor.com.br/torcedometro)

É interessante observar que clubes como o Flamengo e Vasco da Gama, por exemplo, donos de duas das cinco maiores torcidas do país em números absolutos, primeiro e quinto respectivamente, não conseguem obter desempenho similar com outros clubes de grandeza parecida na prática de sócios torcedores no meio do futebol. (http://www.lance.com.br/futebol-nacional/flamengo-segue-com-maiortorcida-mas-vantagem-para-timao-cai.html)

O Clube de Regatas do Flamengo possui em torno de 33 milhões de torcedores segundo pesquisas ao redor de todo o mundo, possuindo assim uma grande oportunidade de tentar atingir o máximo de torcedores possíveis que possam vir a serem prospectos sócios ativos do clube.

O Flamengo atualmente ocupa a sexta colocação no ranking, denominado "torcedômetro", com "apenas" 97.893 torcedores ativos que contribuem mensalmente com o clube, mostrando a ineficiência do programa atual praticado pelo clube.

O presente estudo pretende analisar o por quê de tal fato ocorrer, visto a grande oportunidade que dirigentes tem nas mãos todos os anos em exercício, de se alcançar uma massa bem maior que atualmente e fazer com que o clube se alavanque de maneira colossal.

Acredita-se que o sucesso de tal prática esteja relacionado a algumas sazonalidades do esporte que, por ser muito cíclico, acaba não se tornando uma prática muito sólida e perpétua.

Face ao acima exposto, por que o programa de sócio torcedor do Flamengo não é um sucesso absoluto, visto que, sua torcida é a maior do país? Este é o nosso desafio e a questão que tentaremos responder. 


\subsection{Objetivo do estudo}

Esse estudo tem como objetivo final analisar os fatores que fazem com que um programa consolidado no Brasil e no Mundo, não seja efetivo em dos maiores clubes do país, dono da maior torcida nacional e descrever sobre o resultado obtido acerca das respostas encontradas com base nas premissas estudadas, dar um parecer crítico de avaliação sobre como o estudo foi desenvolvido e se conseguiu chegar a um resultado satisfatório para o publico leitor do mesmo.

Acredita-se que com base nos estudos sobre o futebol em geral, visto como um todo amplamente de fora, nos estudos sobre a prática de sócios torcedores nos clubes e suas ramificações e principalmente desses fatores dentro do Flamengo, que possa se obter o resultado desejado do presente objeto de estudo.

O grande objetivo desse estudo é chegar a respostas concretas sobre o real problema apresentado previamente, para servir de fins estratégicos para os envolvidos em questão. Seria uma utopia engajada poder presenciar possíveis mudanças no modelo de negócio da prática do clube, que estejam contempladas no presente estudo.

\subsection{Objetivos intermediários do estudo}

Para se atingir o objetivo final proposto esse estudo prevê, como objetivos intermediários a serem alcançados:

$\checkmark \quad$ Analisar o público-alvo, ou seja, quem são esses torcedores especificamente, para embasar a construção do instrumento

Essa parte do estudo foca em analisar quem são esses torcedores atuais do clube, ou seja, há quanto tempo esses membros são sócios e o por quê deles terem virado sócios, entre outras premissas que possam ser importante na característica desses membros ativos do clube.

$\checkmark \quad$ Definir o que desejam os atuais sócios torcedores 
Uma das premissas importantes que devem ser usadas em prol do resultado positivo do estudo em questão é observar o que esses contribuintes do clube desejam ter, seja em relação a benefícios ou qualquer outro tipo de relação mais afetiva com o clube; pretende-se identificar como pode ser melhorado para aqueles que já ajudam o clube de maneira grandiosa.

$\checkmark \quad$ Identificar fatores que fazem com que um torcedor se fidelize e vire sócio torcedor do Flamengo

Um de nossos objetivos intermediários mais importantes é identificar os fatores que realmente são importantes na mente desse torcedor "comum" do Flamengo, que faça com que o mesmo se fidelize e seja realmente um pilar no crescimento econômico do clube de coração.

$\checkmark \quad$ Relacionar os motivos que causam uma adesão baixa ao programa em relação à torcida.

Um motivo fundamental de optar pela Análise de Discurso e não apenas pela Análise de Conteúdo é tentar explorar as causas da desproporção entre torcedores e sócios, mesmo em estrato e amostra determinados.

\subsection{Delimitação e foco do estudo}

O estudo limita-se a analisar os diferentes fatores que fazem com que a grande gama de torcedores rubro negros não se tornem sócios ativos do clube e o impacto direto desses torcedores no clube.

O estudo será realizado na cidade Rio de Janeiro, Brasil, no ano de 2017 e somente com torcedores do clube em questão que é o Clube de Regatas do Flamengo.

Talvez não se alcance resultados conclusivos do porque esses torcedores não se tornam um "ativo" real do clube, mas sim, buscar novas 
perspectivas e avaliações sobre perguntas e questionamentos que existem na cabeça dos torcedores do Flamengo.

\subsection{Relevância do Estudo}

A medida com que os programas de sócios torcedores vêem se expandindo fortemente entre os clubes no país na ultima década, se torna relevante estudar o por quê do clube que possui a maior torcida no Brasil, não apresentar grandes números nesse aspecto, investigando a causa de tais fatos ocorrerem.

Acredita-se ser importante não só para o Flamengo, que é o objeto de estudo, mas para outros clubes interessados em saber aspectos que fazem com torcedores se fidelizem ou não a "seus amores" e o por quê de ocorrerem, pode acabar sendo uma ferramenta estratégica que auxilie na tomada de decisão e planejamento no modelo de negócio do programa.

Será relevante o estudo para os amantes de futebol em geral, pois se sabe que os próprios têm interesse em questões "sem resposta" como é o tema proposto aqui nesse documento, esses amantes do esporte se interessariam pelo trabalho executado aqui nessa área, a fim de aprofundar seus conhecimentos futebolísticos.

Outro publico, que mostraria o quão relevante seria esse estudo para os gestores do próprio clube do Flamengo, que poderiam tomar como base os fatos ocorridos aqui, para a remodelagem do programa Nação Rubro-Negra, como é o nome oficial do programa discutido em questão.

Com certeza, as pessoas mais interessadas em se aprofundar no assunto, seriam os próprios torcedores do Flamengo que teriam seus desejos escritos e eternizados a partir do estudo em questão. Seria possível mostrar o pensamento daqueles que não são do programa e tem o desejo de se fidelizar, daqueles que são torcedores e não desejam se fidelizar e daqueles que já são fiéis ao programa, porém tem ressalvas quanto a operação como um todo. 


\section{Revisão de Literatura}

Neste capítulo, serão abordados estudos relacionados ao tema investigado em questão, com a ajuda de aspectos teóricos para maior embasamento do estudo. Como início para o trabalho em questão, muitas foram às vivências e observações, dentre elas a participação do próprio autor do estudo em diferentes momentos que seu clube de coração viveu e pode também através de suas experiências vividas no meio do futebol enriquecer ainda mais o trabalho. Estas experiências geraram curiosidade sobre os fenômenos abordados ao longo do trabalho, dando origem ao problema de pesquisa e à busca por novos conhecimentos.

De inicio será introduzido ao leitor conceitos de marketing de acordo com os principais teóricos sobre o tema proposto, em seguida a essa abordagem geral, será percebida uma visão mais especifica no tema marketing de serviço, que dará referencia as nossas conclusões, relacionada diretamente aos serviços de marketing esportivo.

Conforme formos prosseguindo, visto que, marketing de serviços esportivos é o centro de nosso tema, a próxima parte do estudo, visa entender a influência da marca, desenvolvendo as ideias de autores especialistas no referente estudo (Brand Equit e Brand Image), ligados a esfera de comportamento do consumidor, finalizando assim esse capitulo.

\subsection{Marketing}

O estudo do Marketing vem sendo discutido e aprofundado desde seu começo, no início do século XX. Segundo Bartels (1998), nessa época o mercado tinha a preocupação com a distribuição e o acesso aos produtos em relação ao consumidor.

De acordo com o mesmo autor que falamos anteriormente, o gerenciamento de marketing se dá início nos anos 30 e 40. Desta maneira, podemos observar que esse estudo começa a se relacionar em 
conjunto com outras práticas dentro das organizações, sempre com o lucro a longo prazo como objetivo principal. Trinta anos depois, da década de setenta em diante, o marketing começa a olhar também para o ambiente e não só visando o lucro a longo prazo, como por exemplo, atitudes voltadas ao comportamento do consumidor. Com a passagem com tempo, esse estudo foi se consolidando ainda mais, e por volta dos anos 90, o cliente passa a ser o foco das empresas, onde o relacionamento acaba sendo o mais importante, visando uma relação próspera e duradoura com o mesmo. (MCKENNA, 2000).

Segundo Kotler e Keller (2006), a satisfação humana e social é o que envolve o marketing. Resumidamente, podemos falar que ele visa suprir necessidades de modo lucrativo.

A American Marketing Association (2004) trabalha a seguinte definição: "o marketing é uma função organizacional e um conjunto de processos que envolvem a criação, a comunicação e a entrega de valor para os clientes, bem como a administração do relacionamento com eles, de modo que beneficie a organização e seu público interessado".

De acordo com Kotler e Armstrong (2003), tendo em vista o olhar de dentro do ambiente de negócios, a principal tarefa do marketing, é a interface com o consumidor. Criar, comunicar, entender e proporcionar ao cliente a percepção de valor e satisfação que integram a premissa da prática e do pensamento do marketing moderno.

Baseado ainda nos pensamentos dos autores citados acima em algumas passagens, boa parte do pensamento da maioria das pessoas, acredita as funções do marketing se limitam a vendas e propaganda, pura e simplesmente, tendo em vista que, rotineiramente recebemos informações comerciais de diferentes tipos de mídias. Claro, que essas duas ferramentas são de extrema importância para o marketing de maneira geral, porém, são apenas duas, dentre varias outras que integram o marketing na sua totalidade e não necessariamente, essas citadas são as de maior importância. 


\subsection{Marketing de Serviços}

Da mesma forma como foi abordado no tópico anterior, onde foram trabalhados conceitos gerais de marketing de acordo com grandes teóricos sobre o referente tema, neste tópico serão expostos alguns novos conceitos chaves sobre mais uma função, dentre as outras tantas que o marketing possui, o marketing de serviços.

Contudo, como nessa pesquisa, tivemos um tópico exclusivo para tratar sobre as definições do marketing, acredita-se necessário um maior entendimento sobre serviço em si, com isso, serão apresentados a seguir alguns conceitos sobre o tema em questão.

Kotler (1998) acredita que serviço, como qualquer atividade ou benefício, exclusivamente intangível, que uma parte oferece a outra sem que este se torne tangível em algum bem sob qualquer hipótese. Essa prestação de serviço não está necessariamente ligada a um produto físico, ainda segundo o autor citado.

Serviço pode também ser um termo utilizado para identificar setores básicos da economia, o setor agropecuário e o setor industrial que se identifica como primário e secundário. (BANDEIRA et al 1998 apud MASTELLA 2006).

A economia global, cada vez mais vem mostrando a força e a importância do setor de serviços, pois sua capacidade de faturamento é altíssima e também pela geração de novos empregos, alcançando a marca de mais da metade da mão de obra efetiva nos países desenvolvidos.

Reis (2001) mostra o quanto o mercado interage a novos serviços, produtos e tecnologias. Tais serviços sempre relacionados a maior funcionalidade, menor consumo de tempo e a inovações. Contudo, conhecer o conceito de serviço é de extrema importância para o conhecimento da essência das diversas atividades que cercam o mesmo.

De modo geral, as empresas de serviços, que fazem parte de um mercado em franco crescimento, que é considerado o ramo que mais cresce no século 21, ultimamente continua produzindo em diversas áreas, continuadamente se utilizando da capacidade do ser humano em inovar 
sempre, buscando satisfazer as individualidades de cada um, das organizações e familiares (SILVA 2001).

De acordo com Bateson \& Hoffman (2001) e Lovelock e Wright (2003), serviços andam de mãos dadas a rotina da sociedade, seja ela feita ao falar com alguém pelo telefone, a usar a energia elétrica, uma simples ida a faculdade, utilizar uns transporte público ou assistir televisão, entre outros exemplos presentes em nosso dia a dia.

Segundo Zeitham e Bitner (2003) serviços são processos, atuações e ações. Já Kotler e Keller (2006) acreditam que o serviço seja qualquer desempenho ou ação exclusivamente intangível, que não se torna propriedade, podendo ter ou não uma ligação com um produto concreto.

Segundo Gronroos (2003), serviço se trata de um fenômeno complexo. Para o mesmo, essa definição possui muitos significados distintos. O próprio define serviço como um processo de varias atividades em sua maioria intangíveis, que precisam da interação entre os consumidores e os funcionários prestadores de serviço ou de bens físicos normalmente.

Lovelock \& Wright (2003), acreditam que os serviços podem ser melhor compreendidos como um desempenho ou uma determinada ação entregue por uma parte a terceiros. Se o processo estiver relacionado a um produto físico, isso não muda a sua natureza, seu atributo é exclusivamente intangível e com certa frequência não resultam em propriedades ligadas a produção. Os autores citados acima ainda explicitam a constante alteração com que o setor de serviço da economia passa, não sendo comum só ao Brasil, mas sim, em todo o mundo de um modo geral, onde atualmente representa o maior segmento da economia. Entre essas e outras, é importante mencionar também, que o setor de estudo é o grande responsável pelo franco crescimento de novos empregos no país, seguindo a risca praticas já utilizadas em países mais desenvolvidos que tem grandes indústrias no setor.

Segundo Denton (1991), existem pontos cruciais para se obter boa qualidade na pratica de serviços.

Como se conduz gerencialmente uma empresa é o primeiro ponto a ser abordado pelo autor, onde segundo ele, essa condução deve ter um 
objetivo claro, que seja transmitido da melhor forma a todos os integrantes do ambiente empresarial, visando a necessidade do foco comum a todos. O segundo ponto, é mais complexo, onde ele trabalha com a premissa de que o serviço deve ser entendido de forma sistemática, para facilitar o discernimento dos integrantes da empresa nas execuções das tarefas e, com isso, ter a certeza da qualidade garantida na execução do serviço e trazer o cliente para dentro desse processo. $O$ terceiro ponto trata das pessoas, que são essenciais para contornar falhas que possam ter sido cometidas anteriormente, pelo fato de terem esse contato direto com o consumidor e a técnica necessária na condução das ações. Por ultimo, porem, não menos importante, o quarto ponto expressa a importância na escolha das pessoas mais qualificadas e em suas habilidades para o bom desempenho de cada etapa listada acima.

De acordo com as teorias de marketing expostas no começo deste capitulo, e segundo Zeithaml e Bitner (2003), existe o famoso Mix de Marketing, que é classicamente integrado por: Produto, Preço, Praça e Promoção, vulgarmente conhecido como os "4 Ps". Esses indicadores do Mix visam a satisfação daquele cliente e principalmente na otimização dessa troca na comunicação com esses consumidores (ZEITHAML e BITNER 2003). Continuando na mesma linha, de acordo com os autores, tratando-se de serviços, mudam-se esses "4 Ps" para "7 Ps". Esses novos elementos desse Mix de Marketing são eles: Pessoas, Evidências Físicas (Physical Evidences) e Processo.

Pelo mesmo raciocínio anterior, de acordos com os autores citados acima, o processo de decisão de compra por parte desse prospecto consumidor final, fatalmente será diferente e alterada, devidos aos novos "3 Ps" referente aos marketing de serviços, por já fazerem parte tradicionalmente sendo utilizados por peças chave da organização prestadoras de serviços nesses momentos críticos.

Kotler e Armstrong (2003), afirma que uma companhia deveria considerar certas premissas exclusivas a serviços, como: Variabilidade, Intangibilidade, Perecibilidade e Inseparabilidade, seguindo a figura 1 abaixo. 
Figura 1 - As 4 características dos serviços

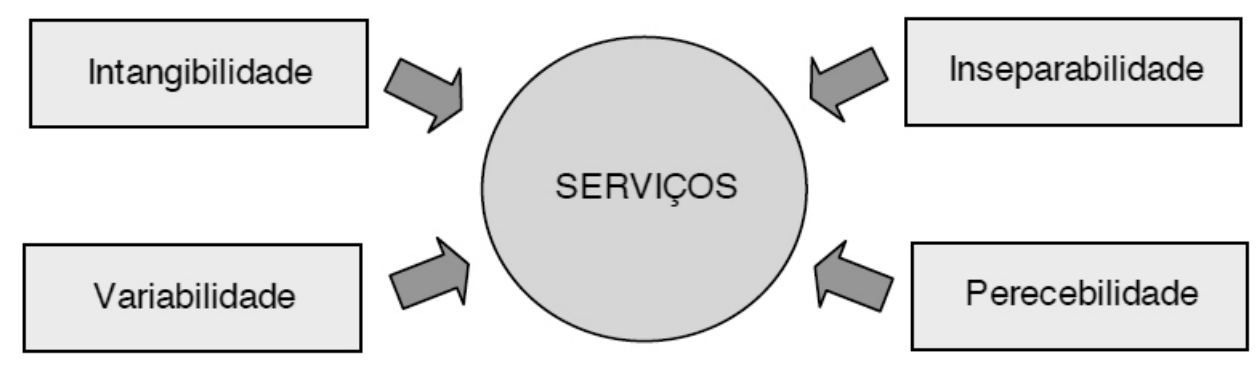

Fonte: Kotler e Armstrong (2003)

Segundo Urdan (1995), autor que descreveu uma pesquisa com as principais características dos serviços e consequentemente foram aperfeiçoadas por Grönroos (2003), tendo uma ideia consolidada e global dessas características especiais:

- Intangibilidade;

- Não pode ser revendido;

- Não pode ser efetivamente demonstrado antes da aquisição;

- Não pode ser estocado;

- Produção e consumo simultâneos;

- Produção, venda e consumo são espacialmente unidos;

- Não pode ser transportado;

- Cliente é parte da produção;

- Na maior parte dos casos, o contato direto é necessário;

- Valor principal é produzido nas interações entre vendedor e cliente.

\subsection{Comportamento do Consumidor}

O comportamento do consumidor, para Solomon (2011, p.33) "é o estudo dos processos envolvidos quando indivíduos ou grupos selecionam, compram, usam ou descartam produtos, serviços, ideias ou experiências para satisfazer necessidades e desejos".

A partir dessa analise de Solomon, como poderá ser visto ao longo do trabalho, o comportamento do consumidor é diretamente ligado com o estudo em questão, pois é exatamente o comportamento do consumidor 
de artigos esportivos em geral, mas precisamente, o torcedor do Flamengo, como esse cliente se relaciona e se identifica com o clube, e quais fatores são levados em consideração no comportamento de consumo dele.

Pode-se compreender necessidade como um motivo biológico básico e o desejo como o modo que nos foi ensinado pela sociedade para satisfazer essa necessidade. Ou seja, a necessidade já existia inicialmente. Assim, a tarefa dos profissionais do marketing consiste simplesmente em recomendar modos de satisfazer as necessidades a partir de sua identificação. $O$ marketing não objetiva criar tais necessidades, mas sim criar a consciência de sua existência (SOLOMON, 2011).

Mais uma vez é possível observar através das palavras de Solomon, que os desejos já existem dentro do possível cliente, mesmo que o próprio não tenha conhecimento disso. Devido a isso, trazendo para a pratica dentro de nosso tema, será interessante observar quais práticas e desejos o clube criador do programa, pode embutir dentro da cabeça dos possíveis próximos consumidores dos serviços e produtos que o programa oferece.

\subsection{Comportamento do Consumidor Como Fã}

A percepção de fidelidade a marca, no futebol em si, pode ser entendida como um produto, quando o representante da marca é o clube e o consumidor final é o torcedor (PARKER, STUART, 1997).

Segundo Van Zoonen e Oppenhisen (2006), no começo do século 21, foi aberta uma discussão importante e precisa, ligada ao status de torcedor nos negócios do mercado esportivo: qual seria o certo a se afirmar, que esses torcedores eram partidários ou clientes realmente de seus respectivos clubes? Segundo os autores, a pergunta é muito complexa e não existe uma resposta exata.

Segundo Santos (2008), ao analisar um torcedor de futebol como cliente, o entendimento sobre esse consumidor não é o mesmo comparado a clientes tradicionais, devido as suas características muito 
particulares que o diferem dos outros. O autor entende deste modo, pois os fatores influenciadores destes torcedores são peculiares, devido à paixão devota desses "clientes especiais", carregando emoção e cumplicidade a flor da pele consigo, fora outros aspectos como a lealdade extrema, os grupos sociais em que estão inseridos e a percepção de qualidade atrelada ao impacto da performance esportiva.

Segundo Mayer (2010), não existe julgamento para a tamanha fidelidade desses apaixonados por seus clubes de futebol, conforme o autor, eles são uma forte fonte de receita para os clubes, devido a sua fidelidade, comprando ingressos para jogos, produtos licenciados e em parte alguns se tornarem sócios torcedores. Para Gladden e Funk (2002), o consumo incontrolável de cunho esportivo é ligado ao emocional e experimental, onde não envolve benefícios tangíveis.

Segundo Jacobson (2003), compreendendo melhor tudo que envolve a fidelidade desses torcedores, o autor se utilizou da psicologia dentro do esporte, onde o ajudou melhor a entender e explicar essa construção de identidade de um consumidor do esporte como fã. Seguindo essa ideia da psicologia, ele acredita que essa identidade social muda a maneira desses torcedores de se comportar, buscando serem percebidos como gostariam pelos outros e por eles mesmos, inserido nesse ambiente. Por outro lado, acredita-se também que segundo a identidade social, esses indivíduos se sacrificam de tal forma a conquistar o relacionamento com as outras pessoas similares ou iguais a ele, permitindo até que esses indivíduos sejam melhores do que eles próprios.

Com isso, podemos afirmar que segundo essa teoria exposta acima, possamos entender o motivo desta luta de alguns torcedores de se verem dentro de um grupo social especifico ao invés de outro, falando sobre os clubes, além disso, se enxergamos as características mais atuais sobre este assunto, conseguimos ver e entender os motivos de alguns torcedores mais apaixonados a aderirem aos programas de sócio torcedor de sua agremiação de coração e com isso se ver acima dos outros torcedores "normais" do clube. Desta forma, os especialistas da área levantam aspectos para identificar quais os fatores que levam tais torcedores atuais a terem essa participação mais influente dentro de seus 
clubes, como ativos do clube realmente, aumentando assim a fidelidade entre os elos.

Tal fidelidade exposta no texto acima ressalta os olhos, quando observamos a percepção desses seres humanos enfrentando as diferentes situações de jogo, como derrotas e vitorias, levando para suas vidas como se fossem pessoais realmente (Gwinner e Swanson, 2003).

Mais uma vez conforme os pensamentos de Jacobson (2003), acredita-se em dois níveis de influencia sobre a identificação deste fã do esporte e sua relação com o clube de coração. Segundo o autor, o primeiro nível se encontra na relação interpessoal, onde a rivalidade com colegas de trabalho, parentes e amigos fala mais alto, pela motivação em defender seus clubes vem a tona. Já o segundo nível é mais simbólico, que são ligados a fatores que incentivam esse individuo, como as cores, nome, marca, símbolo, hino e algum ídolo especifico.

Pensando por outro lado, Tapp (2004), acredita que o futebol seja um produto imprevisível e que um modelo de negocio baseado nele não possa ter regras. Segundo o autor, o marketing se limita demais devido a essa inconsistência que o futebol reside.

A lealdade do torcedor carregam fatores de cunho psicológico, como a identificação social e emocional, o que a marca simboliza, histórico, imagem própria e hábitos para Lin e Lin (2008). Ainda conforme o autor, devido a essas características, estes torcedores apresentam traços mais fieis a seus clubes, independente do resultado dentro de campo.

Devido a todos esses fatores apresentados acima segundo especialistas no assunto, acredita-se que essa lealdade deva ser medida baseada nos aspectos psicológicos e emocionais dos indivíduos inseridos no meio de estudo, como hábitos do consumidor, variação de resultados do clube e histórico nas competições disputadas.

Conforme outros autores citados acima, também é visto que independente do resultado ser negativo dentro de campo, essa marca do clube não muda com relação a qualidade para manterem esses consumidores - torcedores fieis. Devido a essas exclusividades desta área, é imprescindível para essas agremiações saberem se utilizar dessa 
fidelidade inesgotável para transforma-los em ativos e geradores de valor para o clube.

Um fato bem contemporâneo que vem ocorrendo com frequência em nosso país, é o aumento inacabável de transmissões de jogos e campeonatos internacionais no Brasil, que acaba criando novos entrantes para o mercado esportivo. Acredita-se que desde 2016, este fenômeno vem ganhando força e se fazendo presente, segundo os autores. Em sua maioria, crianças começam a se identificar e criar ídolos em clubes não locais como Barcelona, Chelsea, Bayern, Juventus, entre outros em detrimentos dos clubes de sua cidade. Fatalmente, esta atitude recente impacta diretamente na fidelidade ligada a esses clubes e passam a ter importância que deve ser explorada pelos profissionais de marketing.

Portanto, os profissionais de marketing devem ter conhecimento especifico e explorarem o lado apaixonado destes torcedores mirins principalmente, a modo de tentar trazer esses possíveis futuros consumidores para serem fieis dos clubes locais e não de clubes internacionais e globalizados, este fenômeno é uma ameaça real a médio/longo prazo.

Sendo assim, segundo Tapp (2004), acredita que a presença destes torcedores leais a seus clubes no estádio, pode varias de acordo com as aspirações do time no jogo ou na competição em que está inserido, independente de nosso conhecimento inicial de que o fã seja fiel ao extremo a sua agremiação. Com isso, segundo o autor em questão, a lealdade deste torcedor é posta em duvida como garantia, independente dos fatores situacionais em que o time se encontra.

\subsection{Processo de Decisão de Compra}

A teoria sobre o processo de decisão de compra mais aceita dentre a maioria dos autores é a de cinco etapas que separa em cinco distintos momentos as etapas de compra de um consumidor: reconhecimento do problema, busca de informações, avaliação de alternativas, decisão de compra e comportamento pós-compra (KOTLER, KELLER, 2006; 
SOLOMON, 2001; BOONE, KURTZ, 2009; SHETH, MITTAL, NEWMAN, 2001).

Acredita-se então que a partir dos autores citado acima, existe todo um processo na decisão de compra do consumidor passando por algumas etapas de extrema importância para tal aquisição.

Com relação ao reconhecimento do problema, segundo Mowen (1995), vários fatores podem influenciar o estado desejado ou as aspirações de um consumidor. Entre eles, pode-se citar a cultura, grupos de influência e estilo de vida. $O$ autor cita o exemplo de um estudante que entra na universidade. Ele sente necessidade de mudar seu comportamento, sua maneira de vestir e seus hábitos, adequando-se ao novo ambiente.

Com relação ao que disse Mowen, é muito forte no meio do futebol a cultura e os grupos de influencia, pois, devido a esses grupos, seu processo de tomada de decisão pode mudar de acordo com o momento ou cultura exercida em você, muito interessante observar este ponto discutido por Mowen.

Já quando falamos na busca de informações, segundo Mowen, novamente destaca dois tipos de busca de informação: interna e externa. $\mathrm{Na}$ busca interna, o consumidor tenta recuperar de sua própria memória informações sobre diferentes alternativas de um produto ou serviço. A busca externa refere-se ao rastreamento de informações no ambiente através, por exemplo, da propaganda, da observação, de amigos ou de vendedores.

Pode-se analisar que a busca externa pode ser um fator determinante e importante na decisão de compra do consumidor, para o futebol isso se torna uma informação muito relevante, que pode ser explorado por meio de amigos, propaganda, internet e outros tantos.

O próximo passo é a avaliação das alternativas que segundo Solomon, mesmo com esse conjunto de produtos que pode ser evocado de sua mente, a escolha pode, não obstante, ser influenciada por informações como experiência anterior com o produto, informações presentes na hora da compra, e crenças sobre as marcas que tenham sido criadas pela propaganda. 
Ou seja, a sua crença naquele clube que você carrega desde a infância dentro de você, cultivando a paixão, pode se tornar essencial na decisão de compra, mostrando a relevância dessa etapa desse processo.

Chegando ao passo da decisão de compra em si, este é um dos campos mais importantes no estudo do comportamento do consumidor. Envolve a análise de como as pessoas escolhem entre duas ou mais opções de compra, levando em consideração que uma compra é uma resposta para um problema do consumidor (SOLOMON, 1996). Melhor dizendo, este processo do cliente vem de encontro ao campo teórico que estamos estudando, incluindo o estilo de vida da pessoa, as atitudes, a percepção na mente daquele consumidor e todos os mais diversos fatores emocionais e motivacionais que podem influenciar diretamente ou indiretamente, na correta tomada de decisão por parte do consumidor.

Se tratando de futebol, sabemos que nesse meio em especifico, tudo relacionado a paixão e emoção, ficam minúsculos para expressar os sentimentos que correm nas veias dos torcedores, aumentando ainda mais tais fatores motivacionais no processo de tomada de decisão.

Para Kotler (1998) após comprar o produto, o consumidor experimentará algum nível de satisfação ou de insatisfação. Quanto mais satisfeito estiver o consumidor, maior será a probabilidade de repetição da compra. Outro efeito positivo seria a possibilidade de recomendação do produto a outros consumidores.

Vindo de encontro com a sazonalidade com que o programa de sócio torcedor encontra, é possível observar que deve-se atingir um nível de excelência em que não dependa da fase em que o time vive, para se ter um aumento ou a manutenção do numero de sócios, e sim apresentar um serviço de qualidade que independa do momento dentro de campo que o time passa.

\subsection{Brand Equity}

Conforme já foi expressado de algumas maneiras anteriormente por autores especializados no assunto, este tópico será desenvolvido para o 
entendimento de conceitos relacionados ao valor da marca e da imagem que ela representa.

Antes de mais nada, será exposto o conceito de marca do seu inicio para um maior aprofundamento no decorrer do tópico. Farquhar (1989) afirma que essa importância de marca que existe hoje, se deve ao surgimento no antigo Egito, e a partir do século 18 começa a evoluir esse conceito com a exposição dos nomes das marcas para melhor associação junto ao comprador.

Segundo outro autor renomado, Kotler (2006) acredita que a marca pode ser estendida a outros fatores, como: design, símbolo, nome ou a junção de todos estes ou alguns, para serem identificados como bens e serviços de quem vende, consequentemente para serem facilmente reconhecidos e diferenciados da concorrência dentro do ambiente vivido em questão.

Já Jacoby e Kyner (1973) afirmam que o comportamento de cada individuo que é primordial para a fidelidade a marca, pois independente do numero de concorrentes conhecido, o consumidor não tem um consumo aleatório.

Segundo (AAKER, 1991), andando paralelamente ao conceito de marca exposto acima, é essencial a atenção de que o valor da marca é medido pelo valor percebido do consumidor leal e consequentemente, essa lealdade pode virar valor para a empresa detentora da marca.

Ainda nessa mesma toada, segundo o autor acima, acredita-se que por seus respectivos clientes expressarem suas personalidades e estados de espírito através de suas marcas, é nesse fator que as marca deve estabelecer um relacionamento prospero e solido com esses consumidores. Um exemplo real sobre o assunto comentado acima, é o famoso caso da Harley-Davidson e seus clientes mais que fieis, onde esses indivíduos muitas das vezes eternizam o nome da marca em suas peles, como forma de tatuagem, mostrando quanto de amor envolve esses consumidores. O mesmo ocorre frequentemente com torcedores que fazem o mesmo com seus times.

Um caso de sucesso que representa bem o parágrafo acima, entre a relação de um clube com seus torcedores que foi realizada pelo Club de 
Regatas Vasco da Gama. Uma campanha foi criada com o intuito de tatuar a Cruz de Malta (símbolo do clube) em torcedores apaixonados e em troca receberem uma camisa oficial do clube. Campanha que teve êxito ao aglomerar inúmeros torcedores dispostos a tal proposta. (https://oglobo.globo.com/esportes/vasco-na-pele-comecou-nesta-sextafeira-3026573>. Acesso em 8 de abril de 2017).

Keller (1993, P.2) defende que "um dos ativos mais valiosos para melhorar a produtividade do marketing é o reconhecimento de uma marca perante o mercado e seus consumidores a partir de investimentos anteriores". Devido a isso, essa característica em especial deve ser considerada fortemente quando um clube de futebol é o assunto em questão, pois estratégicas visando o maior lucro ao longo do tempo podem ser adotadas, ainda mais caso o clube seja um time de renome e reconhecido por suas glorias no decorrer da historia.

Segundo o autor exposto acima ainda, ele afirma que é preciso a execução de quatro ações diferentes para uma marca se tornar forte. A primeira ação é estabelecer um símbolo forte que faça com que a marca tenha uma identificação mais rápida junto ao consumidor e ligado a isso uma associação a uma categoria especifica de serviços e/ou produtos. A segunda ação é colocar na cabeça do cliente, ou seja, fazer com que o consumidor perceba a sua marca em sua mente que a marca exerce a função com um significado claro de associação a bens tangíveis ou não. Posteriormente a isso, a marca deve forçar aos clientes respostas referente a seu significado ou identidade. E por ultimo, segundo o teórico, é a necessidade da criação de fidelidade entre os elos de cliente e marca, na medida em que a mesma responda as necessidades recebidas.

Conforme Lin e Lin (2008), o consumidor satisfeito é primordial na construção de fidelidade entre cliente e empresa, apresentando traços positivos referente a marca. Segundo os mesmos autores supracitados acima, muitos aspectos estão ligados a essa balança entre expectativa e a superação dela, que consolidam a satisfação, por exemplo: custo, confiabilidade, expectativa, emoção, clareza, satisfação, variabilidade, risco, influencia do meio, reputação da marca, entre outros. A marca vai 
ganhando um maior valor percebido na mente dos consumidores na mesma proporção que a satisfação desse consumidor vai aumentando.

O valor da marca esta relacionado diretamente ao conceito de brand equity. Segundo Farquhar (1989) o valor agregado que a marca atinge ao fornecer seu produto, significa brand equity. Ainda de acordo com o autor citado, esse mesmo valor tem sua medição atrelada a perspectiva do negocio, do cliente e da empresa. Falando mais da área da contabilidade, a companhia visa avaliar o valor da marca segundo um fluxo de caixa especifico, chamado fluxo de caixa incremental, que é associado a marca e o produto e a rentabilidade provida de ambos. Pelo ponto de vista do business, acredita-se que se deve ressaltar a capacidade de tal marca em conseguir persuadir e influenciar outras marcas do mesmo segmento, além de consumidores também. Por ultimo, mas não menos importante, existe o consumidor e sua perspectiva única, onde a analise é feita pela intenção de compra ou pelo volume da mesma.

A classificação de brand equity pode ser dada como o porquê dos consumidores se sujeitarem a pagar preços mais elevados por determinado serviço ou produto de uma marca especifica em detrimento de outras do mesmo ramo (Aaker, 1992). Segundo o mesmo autor, este conceito em questão pode ser melhor explicado em quatro palavras distintas entre si, para se ter diferentes dimensões dentro do mesmo conceito, como: associações, lealdade, qualidade percebida e percepção da marca para quantificar o conceito.

Já segundo Feldwick (1996), a expressão brand equity se utiliza de três usos diferentes entre si. O valor geral da marca visto como um ativo real da empresa é o primeiro uso que o autor enfatiza, o segundo é referente a fidelidade entre os clientes e a companhia perante a forca dessa relação em questão e o terceiro e ultimo, pela percepção dos clientes junto a marca, ou seja, a crença deles sobre a marca.

Segundo Aaker (1992) novamente, para maior entendimento do conceito, foram expostas acima varias definições e indagações a respeito de brand equity, é interessante observar os principais fatores levados em consideração para o estudo de tal conceito, como: as estratégias de marketing visando o aumento da produtividade e o aspecto financeiro. 
Falando sobre as estratégias de marketing, é interessante ressaltar que para ser melhor entendida, deve-se considerar os custos altos, forças dos grupos sociais como agentes de influencia, desafios mercadológicos gerais, competitividade e demanda de queda em alguns mercados. Já com a visão para as finanças, deve se ter atenção na hora de fazer prospecção de valores ligados a marca como ativo e qual o impacto na contabilidade da empresa e também não esquecendo de futuras negociações relacionadas a aquisições ou fusões. Com relação ao que foi exposto acima, é de extrema importância o maior entendimento sobre esse consumidor especifico de tal nicho, que é um fã propriamente dito, sobre suas percepções em decorrer do valor real dessas marcas dos clubes brasileiros, porque principalmente no Brasil, as agremiações são vistas previamente por esses torcedores como marcas com infinitas dividas publicas, gestões não profissionais e de baixa confiabilidade.

O conceito de brand equity além de tudo já falado, carrega com si uma ligação direta a imagem (brand image) que tal marca é percebida pelas partes interessadas (stakeholders), com isso, é de grande interesse da marca tentar prospectar como ela vista na cabeça dos consumidores dentre do ambiente em que esta inserida.

Ainda conforme o mesmo autor citado acima, aprofundando mais um pouco ainda sobre as dimensões faladas anteriormente, o autor ressalta a diferença entre valor contábil e valor de mercado, o que consequentemente acaba se tornando um fato relevante de estudo sobre essa analise dos diferentes aspectos que levam na construção do valor da marca e essa força pelos profissionais de marketing.

\subsection{Brand Image}

KELLER (1993) acredita que brand image mesmo não tendo uma visão igualitária dentro dos pensadores da área, é possível garantir que necessariamente para a criação da imagem da marca, essa imagem esteja interligada por algo na cabeça do consumidor. Devido a isso, a natureza dessa ligação poderá modificar a forma como os tantos tipos de informação são ligadas a marca. 
O brand image nada mais é que a percepção mental e exclusiva que o cliente constrói sobre todos os valores de uma suposta marca em relação as concorrentes do mesmo ambiente de disputa, ou seja, se trata das inferências formadas por esses consumidores e o modo como o cliente se relaciona emocionalmente com a marca. (Faircloth, 2005)

Iversen e Hem (2008), afirmam que o brand image é fundamental quando ligado as crenças e as expectativas geradas pelos clientes em questão em relação a um serviço, produto ou até fatores intangíveis.

"Percepções acerca dela refletidas por brand associations existentes na memória do consumidor" (Keller, 1993). Conforme o mesmo autor, o aumento de consumo da marca está diretamente relacionado a imagem positiva percebida pelos seus clientes em questão, tal característica é primordial na construção da fidelidade desse cliente com a marca e enfraquece a chance de haver trocas para marcas concorrentes diretos ou indiretos por ações promocionais por exemplo, visando "roubar" seus leais consumidores. Reforçando esse caminho em busca da consolidação de um positivo brand image da marca, a empresa dona da marca poderá ser capaz de obter maiores margens no ganho total, por poder precificar de maneira mais livre e sendo assim quantificar a elasticidade de sua demanda ao que se refere ao aumento de preços.

A construção positiva da imagem de uma marca, quando consolidada, existe o fenômeno de que as mensagens expostas por essa marca bem sucedida no brand image, passa a ter mais influencia em seus consumidores na comparação em detrimento dos concorrentes diretos da mesma (Lee et al, 2011). Ainda conforme o mesmo auto, esses consumidores fieis que acreditam piamente na mensagem recebida pela marca, passam a se tornar defensores da marca por vontade própria, devido a imagem que construíram em sua mente e assim sendo, protegem a marca em todas as circunstancias em alguma eventual discussão ou discordância que possa acontecer dentro do ambiente inserido. Esse fenômeno é muito comum quando nos tratamos de futebol, onde os torcedores de seus clubes defendem a todo custo em qualquer que seja a situação os interesses do mesmo a cerca dos rivais, visando sempre tentar convencer o rival de que ele está correto em sua visão. 


\subsection{Blogs; Revistas; Jornais esportivos e Sites}

Será utilizado também como forma de embasamento de dados e opinião de conhecedores do assunto no mundo do futebol brasileiro como o Blog do Rica Perrone, que carrega uma credibilidade no meio do jornalismo esportivo, o Jornal $O$ Lance, servirá de auxilio também ao estudo com matérias que possam incrementar e enriquecer ainda mais o estudo em questão e a Revista Placar, que carrega um nome e uma tradição que perdura décadas com matérias serias e interessantes sobre futebol em geral também.

Alguns sites serão de extrema importância também para a atualização deste trabalho e auxilio nos números exatos dos fatos, como o site oficial dos programas de sócios torcedores do país, que se chama Movimento por um futebol melhor, dando atualizações de hora em hora sobre as novas adesões em cada clube do Brasil e o site oficial do programa de sócios do Flamengo, que se chama Nação Rubro-Negra, que possui todo o portfolio de serviços, benefícios e projetos presentes e operados pelo clube. 


\section{Métodos e procedimentos de coleta e de análise de dados do Estudo}

$\mathrm{Na}$ administração de empresas o interesse pela abordagem qualitativa começa a se delinear a partir dos anos 70, apontando uma aplicação atual dos tipos ideais do mestre Weber e propondo uma leitura distinta de Marx, Bourdieu e Deleuze. (Vieira, M. FGV, 2004).

Embora nas duas abordagens - quantitativa e qualitativa - a pesquisa se caracterize como um esforço cuidadoso para a descoberta de novas informações ou relações e para a verificação e ampliação do conhecimento existente, o caminho seguido nesta busca pode possuir contornos diferentes. A pesquisa qualitativa parte de questões ou focos de interesses amplos, que vão se definindo à medida que o estudo se desenvolve. Envolve a obtenção de dados descritivos sobre pessoas e processos interativos; pelo contato direto do pesquisador com a situação estudada, procurando compreender os fenômenos segundo a perspectiva dos sujeitos, ou seja, dos participantes da situação. (Godoy, Arilda, UNESP, 1995)

Atualmente, os dois tipos de "metanarrativas" tem igual importância e, no dizer de Peci, "o esforço deste tipo de pesquisa pode inserir-se na tentativa de superação do monismo metodológico e abrir espaço para inovação e ousadia em termos de fontes e instrumentos de coleta de dados, assim como de sua apresentação" (PECl, 2004, p. 30), valorizando a adoção da pesquisa qualitativa como opção metodológica de riqueza e inovação.

Ruediger e Riccio (2008) debatem a utilização dos grupos focais como instrumento de análise qualitativa de alto poder analítico, pois o mesmo caracteriza-se pela possibilidade de intervenção em tempo real no curso da análise e de confrontação das percepções de participantes em suas similitudes e contradições a respeito de um tema ou grupo de temas relacionados ao objeto de pesquisa; é possível enfatizar não apenas as 
percepções individuais, mas também aquela oriunda das interações do coletivo e expressa nas estruturas discursivas e na defesa ou crítica de temas e aspectos relevantes da pesquisa.

Uma grande gama de teóricos enfatizam a utilização da pesquisa qualitativa em marketing e em pesquisas de comportamento do consumidor como o caminho mais rico e interativo. (AYROSA; SAUERBRONN, 2004, p. 196).

\section{TIPO DE PESQUISA:}

\section{Pesquisa de observação participante:}

Este tipo de pesquisa também visa descrever um fenômeno, dando ênfase à situações naturais de observação daquele fenômeno, tal qual ele ocorre naturalmente. Ela procura entender principalmente os processos subjacentes aos dados observados. Trata-se, portanto, de uma pesquisa qualitativa, onde se faz mais inferências sobre o fenômeno estudado. A pesquisa por observação participante implica em uma interação social entre o pesquisador e os indivíduos observados. O pesquisador pode participar da vida do público que ele está estudando, interagir, sem se preocupar com a interferência ou subjetividade. (CONTRADOPOULOS, AP et ali 1990).

\section{Pesquisa Qualitativa do tipo Análise de Discurso (AD)}

O suporte teórico que embasa este texto refere-se à $A D$ que "articula o lingüístico com o social e o histórico", na qual a linguagem é estudada não apenas enquanto forma lingüística como também enquanto forma material da ideologia. Além de que é "no contato do histórico com o lingüístico, que [se] constitui a materialidade específica do discurso". A AD trabalha com o sentido e não com o conteúdo do texto (MUTTI, R, 2005, UFRGS). 


\subsection{Etapas de coleta de dados}

O desenvolvimento da perspectiva qualitativa gerou uma grande diversidade de métodos de trabalho, estilos de análise e a apresentação de resultados e diferentes considerações quanto aos sujeitos. São etapas desta pesquisa:

- Delimitação do público-alvo e método de amostragem - estudo sobre o perfil de consumidor mais adequado ao atingimento dos objetivos propostos.

- Construção do instrumento - baseado em observação direta e percepção do pesquisador sobre o tema, optou-se por uma entrevista guiada e gravada com formulário de apoio.

- Trabalho de campo através de observação, entrevista e formulário - tempo utilizado nos locais de pesquisa, em contato direto com os sujeitos. A entrevista é uma técnica que se caracteriza pela forma de relacionamento humano estabelecida: é um contato direto, face a face, entre duas ou mais pessoas. Na presente pesquisa foi estruturada com formulário de apoio e condução não diretiva.

-Registro dos testemunhos - em gravação de áudio e transcrito em meio impresso.

- Analise dos dados e escrita dos resultados obtidos - incluindo descrições de trechos de conversas e diálogos e remetendo à revisão de literatura. estudo

3.2. Fontes de informação selecionadas para coleta de dados no

O número de questionários e formulários é delimitado a partir do tema e dos objetivos da pesquisa. Padronizou-se os formulários, com dados que identificam o informante (nome, idade e sexo) nos itens iniciais. A pesquisa é classificada como uma teoria de pequenas amostras com $\mathbf{n}=08$. (Para amostras menores do que 30 ), com dois grupos de igual tamanho dentre torcedores sócios do Programa Nação Rubro Negra. e torcedores não sócios. 
A população ou conjunto universo $(\mathrm{N})$ foi delimitado a torcedores do Flamengo no município do Rio de Janeiro. Quanto ao sexo foram todos do sexo masculino. A faixa etária variou de 20 a 50 anos, pressupondo o autor que corresponderia a uma maior variedade de visões do tema, pertencendo toda a amostra a uma classe social média alta ou A2. O período de coleta de dados: 30 dias.

Trata-se, portanto, de uma amostra intencional por conglomerados, já descritos acima.

\subsection{Procedimentos e instrumentos de coleta de dados utilizados no estudo}

O autor realizou as entrevistas na casa dos entrevistados, após o aceite de participação na pesquisa. Esta escolha se deveu a que se pudesse ter um ambiente sem interferências e com clima coerente com a melhor interação entre pesquisador/pesquisado; apesar de estruturada por formulário de apoio, os respondentes não eram interrompidos em suas declarações e consentiram serem gravadas as declarações.

No entendimento do autor, reforçado por teóricos do assunto, é de vital importância na análise de discurso qualitativa se conseguir uma ambiência facilitadora ao alcance dos resultados. A forma de gravação otimiza o uso do tempo, sem delongas e anotações.

O modelo de formulário encontra-se em anexo e as gravações disponíveis em meio eletrônico.

\subsection{Formas de tratamento e análise dos dados coletados para o estudo}

Os dados foram transcritos para o papel; os relatos imprimidos, procedendo-se à análise de discurso, selecionando as mais significativas, após comparação, para serem descritas no Capítulo 4, sempre se retornando às gravações, quando necessário.

\subsection{Limitações do Estudo}

Considera-se apropriado o desenho de método escolhido, pois a pesquisa qualitativa é mais adequada a temas como este onde se tenta 
saber o máximo de informações dos sujeitos e das interações entre eles e o pesquisador e entre os respondentes a partir da análise dos testemunhos.

As possíveis tendenciosidades se devem ao tipo de amostra elegida, a saber, intencional em conglomerados de renda, sexo, escolaridade e mesmo ao tema que, enquanto flamenguista prevê massa e popularidade, mas enquanto sócio do Programa Nação Rubro Negra, já pressupõe acesso à Internet, redes sociais, cartão de crédito e outras características mais estratificadas. Os resultados, no entanto, têm coerência com as características da amostra, não passíveis de transferências automáticas, mas referência para outros estudos. 


\section{Apresentação e análise dos resultados}

\subsection{Relatório da pesquisa qualitativa}

Visando alcançar aos objetivos desse trabalho de conclusão de curso e buscar entender melhor o consumidor direto do programa de sócios torcedores do Flamengo foi necessário aplicar um instrumento de pesquisa visando entender e conhecer esse cliente "fã", bem como suas percepções sobre programa Nação Rubro Negra.

A coleta de informações do nosso público-alvo foi realizada em lugares diferentes, com abordagem qualitativa do tipo análise de discurso, configurando uma amostra intencional por conglomerados, mas em acordo com o objeto da pesquisa.

Dados dos entrevistados:

\begin{tabular}{|l|c|c|l|c|}
\hline Entrevistado & Profissão & Idade & Sexo & Status \\
\hline Luis Felipe & Estudante & 22 & Masculino & Sócio \\
\hline Carlos Eduardo & $\begin{array}{c}\text { Representante } \\
\text { Comercial }\end{array}$ & 48 & Masculino & Sócio \\
\hline Carlos Roberto & $\begin{array}{c}\text { Representante } \\
\text { Comercial }\end{array}$ & 48 & Masculino & \begin{tabular}{c} 
Sácio \\
\hline Ricardo
\end{tabular} \\
\hline Estudante & 22 & Masculino & Sócio \\
\hline Pedro & Estudante & 22 & Masculino & $\begin{array}{c}\text { São } \\
\text { Rafael }\end{array}$ \\
\hline Mauricio & Advogado & 39 & Masculino & Sócio \\
\hline Renildo & Designer & 46 & Masculino & $\begin{array}{c}\text { Sácio } \\
\text { Sócio }\end{array}$ \\
\hline
\end{tabular}

Nas entrevistas foi possível perceber o envolvimento dos consumidores com tal produto, suas prioridades, necessidades, 
reinvindicações, criticas e sugestões, mostrando possíveis soluções para a melhora do programa em questão. Devem ser direcionados esforços para entender as reais necessidades em busca da satisfação plena desse tipo especifico de consumidor, sempre estimulando e valorizando a participação ativa dentro do programa, que pode fazer com que se mude de patamar, tanto negativamente quanto positivamente e estreitamento de laços entre consumidor/empresa.

Percebeu-se, através desta pesquisa, que as opiniões e atitudes perante as perguntas são diferentes, por consequências e influências de suas crenças pessoais, idade, estilo de vida e o meio em que estão inseridas.

Para se ter uma visão mais justa e ampla sobre o programa, foram entrevistados o mesmo numero de sócios e não sócios que conhecem o programa, sempre com a premissa de ser rubro negro de coração.

O conhecimento sobre o programa foi expressivo em todas as entrevistas e a paixão e envolvimento foram sentidas em cada fala e frase dos entrevistados, por se tratar de sentimentos diretamente ligados a laços de infância, lembranças positivas e negativas, entre outros fatores.

Falando mais sobre o programa Nação Rubro Negra em si, foi visto que os sócios ativos do clube demonstraram maior entendimento e satisfação com o desempenho atual do mesmo.

Pode-se observar que a maior preocupação destes sócios torcedores foi em ajudar o Flamengo primordialmente, dando sua contribuição mensal, visando alavancar ainda mais as receitas do clube para ter ganhos no futuro, como bons elencos, boas contratações, entre outras palavras, ver o seu dinheiro ajudando diretamente o seu "clube de coração", o Carlos Eduardo disse:

"Sou sócio para ajudar meu clube de coração, pois gostaria de ajudar e segundo porque dá benefícios também, apesar de não ir muito ao maracanã, mas sei que tem benefícios e facilidades... mas o principal é para ajudar ao clube".

Outro fator importante a ser observado por esses consumidores foi a facilidade da compra de ingressos antecipadamente do público geral e os descontos dados pelo programa, pode-se dizer que é um dos principais motivos percebidos pelos clientes também, como o Luiz Felipe pode 
indagar "Sou sócio pela facilidade de conseguir ingresso para os jogos dentro de casa no setor que eu gosto de ir que é o norte".

Observando pelo ponto de vista de quem está de fora, que foram os entrevistados que não estão associados ao clube atualmente, foi possível observar uma certa reflexão mais profunda deles quando indagados sobre o porquê de não serem sócios do clube.

Percebe-se que a falta de informações e conhecimento do programa em si e suas vantagens oferecidas é um ponto critico para esses torcedores, como o Mauricio falou na passagem a seguir "é uma boa pergunta, pois sempre fui ao maracanã desde a minha adolescência, mas até hoje eu não achei vantagem em ser sócio, não sei quais são elas", ou seja, a falta de divulgação e uma melhor comunicação podem estar atreladas a este motivo de não ser sócio.

Outras questões levantadas por estes entrevistados para não se tornarem sócios, foi a falta de assiduidade aos jogos, demonstrando assim para eles não valer o custo $\mathrm{x}$ beneficio e por não estar entre as prioridades atuais e pessoais de cada um destes entrevistados.

Sobre como os benefícios do programa são percebidos para todos os entrevistados, é quase que unânime que a facilidade e o desconto na hora da compra do ingresso é o maior beneficio de todo o programa, como o Pedro fala a seguir "Eu acho que é a facilidade de comprar ingresso pra jogos importantes, eu como não sou sócio, às vezes tenho vontade de ir, mas não tem, já acabou ou o setor que eu quero não tem mais".

Em decorrer do parágrafo acima, é possível observar que no entendimento destes torcedores talvez os outros benefícios que o programa dispõe, não são bem explorados ou divulgados, a ponto de serem percebidos como reais diferenciais.

À medida que a entrevista continua, é nítida a vontade de cada um deles em poder ajudar com suas opiniões e diferentes visões sobre o que acredita, e quando foram desafiados a dar sugestões de como o programa poderia desempenhar de uma melhor maneira, as respostas foram variadas entre si, demonstrando o quão diferente cada um pensa em detrimento de outra pessoa. 
O que pode ser visto foi que a palavra divulgação e marketing foi citada inúmeras vezes, mostrando uma certa insatisfação com relação à comunicação feita atualmente pela diretoria sobre o programa, como nessa passagem do Rafael:

\footnotetext{
"Camarada, eu acho que para o que ele se propõe, eu acho bom, poderia melhorar sim, não sei, talvez ele pudesse divulgar mais para gente usar os benefícios que ele possui e a gente sempre está tendo que procurar para achar alguma coisa, a gente não é ofertado das possibilidades né".
}

O Pedro possui outra visão sobre o assunto, como por exemplo:

"Eu acho que ele pode dar benefícios mais variados, fora do âmbito esportivo, como desconto em cinema, teatro, festas, não só descontos, mas parcerias fora do âmbito esportivo ou do flamengo ou do futebol".

Importante salientar que o programa já oferece parceiros em seu portfólio, porém acaba sendo pouco explorados por seus contribuintes por desconhecimento do pacote adquirido.

Interessante observar a quantidade existente de parceiros variados que são ofertados para seus sócios ativos e não ativos, demonstrando o objetivo claro de tentar diminuir essa dependência de se conseguir adesões só com base em desempenho dentro de campo.

Vale ressaltar outro respondente que propõe que o Clube explicite o que a contribuição de cada sócio agrega em valor no progresso do time; significa, no dizer do Ricardo que "se divulgasse quanto que se arrecadou só com o programa e, por exemplo, ouvir que tal contratação foi fruto da contribuição do sócio; eu fiz a diferença". É uma relação de pertencimento, de emocional mesclado com o objetivo prático ou financeiro, prosperando a relação.

Foi interessante observar os diferentes pontos de vista dos entrevistados com relação às desvantagens do programa em si, foi percebido que os sócios ativos do clube não viam nenhuma desvantagem no programa, nenhum ponto fraco, como no testemunho a seguir do Rafael "Eu nunca pensei nisso diretamente, mas desvantagem talvez... não sei, não me vem nada na cabeça agora"

Com relação aos não sócios, houveram criticas ao programa, onde foi exposto a limitação do programa no que ele se propõe e o fator principal, que foi dito que o programa só começa a valer a pena a partir do 
momento que você se torna um torcedor assíduo, que compareça a todos os jogos, como falado a seguir pelo Mauricio "na minha visão, como ate hoje eu não entrei para ser sócio, acho que se você não for assíduo em relação a ir aos jogos, enfim, não vale a pena".

Um dos temas principais que são discutidos recorrentemente por especialistas e torcedores país afora é com relação à fidelização desses sócios junto ao clube sem depender do resultado e desempenho do time fora de campo, "a famosa pergunta do século".

Especificamente nesse tema, foi interessante observar as diferentes formas e pontos de vista das pessoas em questão, porém o que chamou atenção foram as diversas citações da cultura do brasileiro e a cultura dos países europeus principalmente em relação ao futebol e o modo com que os torcedores se relacionam com seus clubes durante o ano inteiro.

Diversas opiniões vieram à tona como a prática usada lá fora de vender um pacote com todos os jogos do campeonato previamente, a divulgação e comunicação foram citadas mais algumas vezes; quando abordados sobre este tema, sempre a favor da criação dessa cultura inexistente nessa esfera atual que o futebol se encontra, uma passagem da entrevista do Luiz Felipe exemplifica bem o comentado acima:

\footnotetext{
"Temos que criar a cultura novamente, antigamente as pessoas iam pelo fato de não ter a televisão, só ter o rádio, é criar a cultura de o torcedor ir ao estádio porque a gente vê time pequeno europeu botar 40.000 pessoas todo jogo em seu estádio, acho que é devido a essa cultura criada; tem que ser mais que simplesmente ver o Flamengo jogar e sim o evento esportivo em si".
}

Outro tema de suma importância que vem sendo discutido pelos torcedores e diretores do clube é em relação ao baixo numero de sócios ao tamanho da torcida. Procuramos por meio da entrevista entender melhor o que pode gerar essa baixa adesão ao programa.

Pode-se perceber que as palavras mais usadas para expressar essa fraqueza foram: a falta de acesso às informações e o baixo poder aquisitivo da massa rubro negra. Como é de conhecimento da maioria dos fãs de futebol, sabemos que a maior parte da torcida do Flamengo, a chamada "massa", o "povão", não dispõe das mesmas facilidades que o público consumidor do programa hoje, ou seja, acredita-se que a divulgação do Nação Rubro Negra não esteja atingindo todo o seu publico 
alvo e que ao mesmo tempo possa não estar totalmente flexibilizado para todas as classes sociais que o Brasil apresenta atualmente, como no trecho a seguir que o Pedro disse:

"Eu acho que os benefícios não são tão explícitos, acho que chega a uma margem muito pequena, para pessoas que não tem computador, que não tem fácil acesso a informação, talvez ainda seja algo meio nebuloso, mal divulgado para uma grande massa, acredito que só quem tenha acesso ao programa, são as pessoas que acompanham as redes sociais e vão aos jogos, mas nas comunidades, onde está a grande massa, essa informação não chega, é ai que acredito que esteja essa baixa proporção em relação ao tamanho da torcida",

Chegando a parte final da entrevista, é importante ressaltar a felicidade e orgulho no semblante e nas reações dos entrevistados ao falar sobre o clube de coração.

Depois de todas essas considerações e tantas opiniões similares e diferentes ao mesmo tempo, a avaliação do programa atual teve uma boa aceitação na média e se tivesse uma frase para descrevê-lo, seria: "o programa atende ao que se propõe, tornando-o um bom programa, que contem falhas e pode ser melhorado sempre, porém ao mesmo tempo, é bem quisto entre seus consumidores e não consumidores".

"O relacionamento entre o clube e o torcedor é um alicerce no que se refere ao futebol profissional, pois é desta relação que se determina o potencial de negociação do clube" (Myskiw, 2006). Segundo o autor, o tamanho da torcida e como esses torcedores se comportam por meio de suas atitudes são os fatores primordiais para a geração de receita direta dos clubes.

Importante ressaltar também os preços ofertados atualmente pelo plano e qual o impacto na percepção desses entrevistados sobre este assunto. Pode-se dizer que em sua maioria os mesmos foram declarados como justos mesmo considerando as diversas categorias e a necessidade de escalonar o negócio ao mesmo tempo. Foram levantadas algumas questões sobre a possibilidade de haver planos mais baratos ainda e outras formas de pagamento, mas, de maneira geral, o tema preço teve boa aceitação perante o público consumidor, face ao perfil dos entrevistados. 


\section{Conclusão}

$\mathrm{Na}$ administração de empresas o interesse pela abordagem qualitativa começa a se delinear a partir dos anos setenta, quando se descongela um paradigma de que só o quantitativo tem valor, se descortinando para as ciências sociais possibilidades muito mais completas com enfoque diferenciado.

Optar pela Análise de Discurso na Pesquisa Qualitativa é ousar pensar para além do conteúdo e da linguagem e entendê-la no seu sentido, em meio às relações de poder e a uma Ideologia.

Entender que cada projeto de pesquisa que se inicia traz novos desafios para o pesquisador, que tem que aprimorar seus talentos e habilidades para transpô-los, gerando novas evidências que permitam criar explicações originais, substanciadas e convincentes sobre o relacionamento entre as variáveis.

Acredita-se que o resultado desta pesquisa qualitativa foi satisfatório, visto que foram abordados diversos temas, com diferentes personalidades, com estilos de vida distintos, idades distantes entre si e o mais importante, que foi a realização do estudo com os consumidores inseridos dentro do meio do programa de sócio torcedor e os outros torcedores que estão de fora do meio e podem contribuir com uma visão mais critica talvez em relação aos que aderem.

Todo esse resultado obtido foi de extrema importância para o complemento e o estudo mais aprofundado do tema em questão para uma analise futura sobre o programa Nação Rubra Negra.

Com certeza, vencer desafios é o retorno desejado para a inquietude do pesquisador, que ora se permite, assumidamente, terminar esta conclusão como torcedor e sócio do Clube de Regatas do Flamengo mas, acima de tudo, como uma pessoa que acredita no seu time e na gestão do mesmo, que tem que ser desenvolvida e modernizada, a partir de tantos quantos assumam fazer destas questões, locus de pesquisa. 


\section{Referências Bibliográficas}

AAKER, D. Managing brand equity: Capitalizing on the Value of a Brand Name. Nova lorque: The Free Press, 1991.

ABNT. Gestão da qualidade e elementos do sistema da qualidade Diretrizes. Rio de Janeiro: ABNT, 1990 (NBR 1990).

American Marketing Association, agosto de 2004. Disponível em:

<http://www.marketingpower.com/content4620.php>. Acesso em: 22 de maio de 2017.

BATESON, J., HOFFMAN, D. Marketing de Serviços. Porto Alegre, Bookman, 2001.

CONTRADOPOUlOS, AP., CHAMPAGNE, F., POTVIN, L., DENIS, J.L. e BOUYLE, P. (1990) Savoir preparer une recherche. Montreal les presses de l'Université de Montreal.)

DAMATTA, R. Universo do Futebol: esporte e sociedade brasileira. Rio de Janeiro. Pinakotheke. 1982.

DENTON, D. K. Qualidade em serviços: o atendimento ao cliente como fator de vantagem competitiva. São Paulo, Makron Books do Brasil, 1991.

Diário de Pernambuco, janeiro de 2017. Disponível em:

<http://blogs.diariodepernambuco.com.br/esportes/2017/01/23/os-20clubes-mais-ricos-do-mundo-com-o-manchester-united-no-topo-apos-12anos/>. Acesso em: 20 de março de 2017

DOS SANTOS, F. O VALOR DAS TORCIDAS DE FUTEBOL: 0 CUSTOMER EQUITY DOS CLUBES A PARTIR DOS RESULTADOS DE 
BILHETERIA NO CAMPEONATO BRASILEIRO. Dissertação de Mestrado em Administração de Empresas. Curitiba: UFPR, 2008.

FARQUHAR, P. Managing Brand Equity. Marketing Research, v. 1, p. 24-33, 1989.

FAIRCLOTH, J. Factors influencing nonprofit resource provider support decision: applying the brand equity concept to nonprofit. Journal of Marketing Practice and Theory, v. 13, n. 3, p. 1-15, 2005.

GLADDEN, J.; FUNK, D. Developing an Understanding of Brand Associations in Team Sport: Empirical Evidence from Consumers of Professional Sport. Journal of Sport Management, Champaign, v. 16, $n$. 1, p. 54-81, 2002.

GWINNER, K.; SWANSON, S. A model of fan identification: antecedents and sponsorship outcomes. Journal of Services Marketing, Bingley, v. 17, n. 3, p. 275-294, 2003.

GRONROOS, C. Marketing: Gerenciamento e Serviços, $2^{\mathrm{a}}$ ed, Campus, Rio de Janeiro, 2003.

Histórico Futebol Melhor, junho de 2017. Disponível em:

<http://historicofutebolmelhor.com.br/torcedometro>. Acesso em: 4 de junho de 2017

IVERSEN, N., HEM, L. Provenance association as core value of place umbrella brands: a framework of characteristics. European Journal of Marketing, v. 42, n. 4/5, p. 603 626, 2008.

JACOBSON, B. The social psychology of the creation of a sports fan identity: A theoretical review of the literature. The Online Journal of Sport Psychology, Connecticut, v. 5, n. 2, p. 1-14, 2003.

JACOBY, J; KYNER, D. Brand Loyalty Vs. Repeat Purchasing Behavior. Journal of Marketing Research, Chicago, v. 3, n. 1, p. 1-9, 1973. 
KELLER, K. Conceptualizing, Measuring, and Managing CustomerBased Brand Equity. Journal of Marketing, Danvers, v. 57, n. 1, p. 1-22, 1993.

KOTLER, P. Administração de Marketing: análise, planejamento, implementação e controle. $5^{\mathrm{a}}$ edição, São Paulo, Atlas, 1998.

KOTLER, P. \& ARMSTRONG, G. Princípios de Marketing. 9a ed, Pearson Prentice Hall, São Paulo, 2003.

KOTLER, P. \& KELLER, K. N. Administração de Marketing. $12^{\mathrm{a}}$ ed, Pearson Prentice Hall, São Paulo, 2006.

LIN, Y; LIN, C. Factors Influencing Brand Loyalty in Professional Sports Fans. Global Journal of Business Research, Hilo, v. 2, n. 1, p. 6984,2008

Lance, maio de 2017. Disponível em:

$<$ http://www.lance.com.br/futebol-nacional/flamengo-segue-com-maiortorcida-mas-vantagem-para-timao-cai.html>. Acesso em: 2 de maio de 2017

LOVELOCK, C., WRIGHT, L. Serviços: Marketing e Gestão. São Paulo, Saraiva, 2002.

MCKENNA, R. Marketing de Relacionamento. Rio de Janeiro, Campus, 2000.

MARINHO, I. P. História Geral da Educação Física. São Paulo: Cia. Brasil Editora, 1980

MAYER, M. FUTEBOL: O NEGÓCIO POR TRÁS DO JOGO - ESTUDO DE CASO DO SÃO PAULO FUTEBOL CLUBE. Dissertação de Mestrado em Administração de Empresas. Rio de Janeiro: FGV, 2010

MOREIRA, H.; CALEFFE, L. G. Metodologia da pesquisa para o professor pesquisador. Rio de Janeiro: DP\&A, 2006. 
PARKER, K., STUART, T. The West Ham Syndrome. Journal of the Market Research Society, Londres, v. 39, n. 3, p. 509-517, 1997.

SANTOS, D. Fidelização de Clientes. 2008. Disponível em internet: http://www.administradores.com.br/artigos/marketing/fidelizacao-declientes/20882/. Acesso em 29 abr. 2017.

SILVA, R. T. P. da, Marketing de relacionamento em instituições de ensino superior: estudo de caso no curso de Administração da Universidade do Oeste de Santa Catarina - Dissertação de Mestrado UNOESC - Campus de Videira. Florianópolis: Programa de Pósgraduação em Administração.- Universidade Federal de Santa Catarina, 2001.

TAPP, A. The loyalty of football fans-- We'll support you ever more? Journal of Database Marketing \& Customer Strategy Management. Hampshire, v. 11, n. 3, p. 203-215, 2004.

VASCO na pele. Disponível em:

<https://oglobo.globo.com/esportes/vasco-na-pele-comecou-nesta-sextafeira-3026573>. Acesso em 8 de abril de 2017>.

VIEIRA, M.F. ; ZOUAIN, D.M. Pesquisa Qualitativa em Administração. FGV,2004. 224p. ISBN 85-225-0472-5.

ZEITHAML, V. A. \& BITNER, M. J. Marketing de Serviços: A empresa com foco no Cliente. $2^{\mathrm{a}}$ ed., Bookman, Porto Alegre, 2003. 


\section{Anexo 1}

\section{Formulário de Pesquisa}
1) Qual o seu nome?
2) Qual a sua idade?
3) Qual seu sexo?

4) Você conhece o programa nação rubro negra, referente ao sócio torcedor do flamengo?

5) Por quê você é sócio torcedor do Flamengo?

6) Por quê você não é sócio torcedor do Flamengo?

7) Qual o maior beneficio que você acredita ter no programa?

8) Como você acredita que o programa de sócio do Flamengo pode melhorar?

9) Quais as principais desvantagens do Nação Rubro Negra?

10) Como você acha que o clube pode fidelizar seus sócios sem depender do desempenho do time em campo?

11) Na sua opinião, por quê o número de sócios é baixo em relação ao tamanho da sua torcida?

12) Como você avalia hoje o atual programa do Flamengo?

13) Como você enxerga os preços ofertados atualmente pelo clube? 